\title{
Article
}

\section{Cancer through black eyes - The views of UK based black men towards cancer: A constructivist grounded theory study}

Mulugeta, Betselot, Williamson, Susan, Monks, Rob, Hack, Tom and Beaver, Kinta

Available at http://clok.uclan.ac.uk/17854/

Mulugeta, Betselot ORCID: 0000-0002-8654-3457, Williamson, Susan ORCID: 0000-0002-9635-4473, Monks, Rob ORCID: 0000-0002-9801-3170, Hack, Tom and Beaver, Kinta ORCID: 0000-0002-6552-2323 (2017) Cancer through black eyes - The views of UK based black men towards cancer: A constructivist grounded theory study. European Journal of Oncology Nursing, 29 . pp. 8-16. ISSN 1462-3889

It is advisable to refer to the publisher's version if you intend to cite from the work. http://dx.doi.org/10.1016/j.ejon.2017.04.005

For more information about UCLan's research in this area go to

http://www.uclan.ac.uk/researchgroups/ and search for <name of research Group>.

For information about Research generally at UCLan please go to http://www.uclan.ac.uk/research/

All outputs in CLoK are protected by Intellectual Property Rights law, including Copyright law. Copyright, IPR and Moral Rights for the works on this site are retained by the individual authors and/or other copyright owners. Terms and conditions for use of this material are defined in the policies page. 


\section{Cancer through Black Eyes - The Views of UK Based Black Men towards Cancer: A Constructivist Grounded Theory Study}

\section{Introduction}

The distribution and burden of cancer varies across different groups in society based on income, age, ethnicity and gender (Freeman, 2004; Siegel et al., 2013). In the United Kingdom (UK), men face a significantly higher risk of contracting and dying from nearly all the common cancers that occur in both genders with the exception of breast cancer (Department of Health [DH], 2011; White et al., 2010). Lung, prostate, and bowel cancer are the three most common types of cancer diagnosed in men (Cancer Research UK, 2017a). Prostate cancer disproportionately affects black men compared to any other racial and ethnic group, both in the UK (Ben-Shlomo et al., 2008; Cancer Research UK, 2017b) and the United States of America (USA) (National Cancer Institute [NCl], 2008; Siegel et al., 2013). Lung and colorectal cancer incidence rates are also higher among black men in the USA ( $N C l, 2017$; Siegel et al., 2013). However, in the UK there is no reliable national data on patterns of cancer incidence, mortality and survival in black communities (Gordon-Dseagu, 2009; DH, 2011).

Although there is no evidence to suggest that black men have worse or better access to diagnostic services in the UK (Metcalfe et al., 2008), they are less likely to attend screening (Austin et al., 2009; Rajbabu et al., 2007). The reasons for this discrepancy between the availability and utilisation of services by black men is unclear. A recent systematic review suggested that, while black men bear the highest burden of the disease, limited efforts have been made to ensure they have access to relevant information to support them in making informed decisions to utilise early detection services (Pedersen et al., 2012). Further, studies have shown that there are inequalities between UK black men and the general population in levels of awareness about cancer screening, common risk factors and early warning symptoms (Rajbabu et al., 2007; The Prostate Cancer Charity, 2008; Waller et al., 2009; Webb et al., 2004). However, studies focused on knowledge of, attitudes towards, and views about cancer have used population-based surveys with minimal recruitment of black participants. These studies have not disaggregated the data based on different black subgroups such as black African (BA) and black African-Caribbean (BAC) men. While these quantitative studies have uncovered knowledge about general patterns, such as black men being less aware of cancer risk factors and presenting late, they have not explained the underlying reasons for these patterns. Hence, the 
reasons why black men are less aware of cancer risk factors, warning symptoms and engagement with early detection programmes remains unclear. In addition, how black men understand and view cancer has not yet been fully explored (Waller et al., 2009).

Little is known about UK BA and BAC men's knowledge of, and attitudes towards cancer (Jones \& Chinegwundoh, 2014; Pedersen et al., 2012; The Prostate Cancer Charity, 2008); yet culture can contribute to the way in which people understand, explain and develop their attitudes towards illness including cancer (Burr, 2003; Dein, 2004). Acculturation also affects knowledge and beliefs about illness (Abraído-Lanza et al., 2006). People who migrate to a different country bring with them their own culture, beliefs, values, priorities, and aspirations (Kohnert, 2007). However, healthcare researchers have been slow to recognise the range of cultural and ethnic diversity within the black population (Brown et al., 2011). Hence, current cancer prevention strategies such as public health promotion and early detection strategies may not be sensitive to, address or reflect the cultural beliefs and views of UK-based black men towards cancer, which in turn may affect their awareness of risk factors, early signs and symptoms, and need for early detection. The aim of this present study was to explore the influence of culture on views of cancer held by BA and BAC men living in the UK.

\section{Methods}

The study was conducted using a constructivist grounded theory approach (Charmaz, 2006). Constructivist grounded theory assumes that the interaction between the researcher and participants is an important factor in the research process as it influences the interpretation of meaning that develops from interviews. Preliminary interpretation during the data collection and analysis process involves placing participants' meanings and action at the centre of the process (Charmaz, 2005; 2006).

\section{Sample}

Convenience and theoretical sampling methods were used to recruit participants based on the inclusion criteria (see Table 1). A convenience sampling method was initially used to recruit suitable interviewees based on the inclusion and exclusion criteria shown in Table 1. Once data analysis had commenced and categories began to emerge, theoretical sampling was used to more fully understand the emerging categories, to further develop the emerging theory and to work towards data saturation of emerging categories. 
Table 1: Inclusion criteria

\begin{tabular}{|l|}
\hline Inclusion criteria \\
\hline African-born black men living in the UK \\
UK-born black-African men \\
Caribbean-born black men living in the UK \\
UK-born black Caribbean men \\
Aged 18 years and over \\
Able to communicate in the English language \\
\hline
\end{tabular}

Acculturation may impact on attitudes towards cancer. Hence, we wanted to interview individuals who were foreign born but now resided in the UK (first generation) and those individuals who were born in the UK to foreign born parents (second generation). First and second generation $\mathrm{BA}$ and $\mathrm{BAC}$ participants were recruited though black community organisations from major cities in the UK where large populations of BA and BAC communities reside: Leeds, Manchester, Birmingham, and London. The recruitment process included the use of printed posters and radio advertisements targeting black men.

Twenty-five individuals took part in the study. The demographics of the participants are presented in Table 2. There were $17 \mathrm{BA}$ and eight BAC participants. Eighteen of the participants were first generation (14 BA and four $\mathrm{BAC}$ ) and seven were second generation (three $\mathrm{BA}$ and four BAC). The youngest participants were 19 years old; the oldest was 69 years old. The mean age of participants was 43 years.

\section{Ethics approval}

Ethics approval obtained from the University of Central Lancashire Research Ethics Committee. Interviewees were given participant information sheets (PIS) detailing the study and written informed consent was obtained from each participant prior to the commencement of each interview, and a signed copy of their consent form was given to each participant. 
Table 2: Demographic Characteristics of Participants

\begin{tabular}{|c|c|}
\hline Characteristic & Number of participants \\
\hline \multicolumn{2}{|l|}{ Study area (where participants reside) } \\
\hline Manchester & 8 \\
\hline Birmingham & 5 \\
\hline London & 7 \\
\hline Leeds & 5 \\
\hline \multicolumn{2}{|l|}{ Participant's background } \\
\hline First generation black African (FBA) 1 & 14 \\
\hline First generation black African Caribbean (FBAC) & 4 \\
\hline Second generation black African (SBA) & 3 \\
\hline Second generation black African Caribbean (SBAC) & 4 \\
\hline \multicolumn{2}{|l|}{ Age Range } \\
\hline $19-30$ & 4 \\
\hline 31-39 & 8 \\
\hline $40-49$ & 4 \\
\hline $50-69$ & 9 \\
\hline \multicolumn{2}{|l|}{ Education level } \\
\hline No qualification & 2 \\
\hline Secondary school & 2 \\
\hline A-level & 1 \\
\hline Vocational & 3 \\
\hline Certificate & 1 \\
\hline Diploma & 1 \\
\hline Degree & 15 \\
\hline \multicolumn{2}{|l|}{ Employment status } \\
\hline Full time & 17 \\
\hline Part time & 3 \\
\hline Student & 4 \\
\hline Unemployed & 1 \\
\hline \multicolumn{2}{|l|}{ Length of time residing in the UK by years } \\
\hline $4-10$ & 4 \\
\hline $11-20$ & 10 \\
\hline $21-30$ & 5 \\
\hline Over 30 & 6 \\
\hline
\end{tabular}

1 FBA, SBA, FBAC, and SBAC used as the participant's identification code at the end of each quotation. 


\section{Data collection}

Interviews were conducted using semi-structured questions. A topic guide (see Table 3) was constructed on the basis of the literature review and service user group suggestions. The 'Cancer, Supportive and Palliative Care Research Group' at the host institution works closely with a user and carer research advisory group. This group provided valuable feedback about the content of the interview guide.

Table 3: Topics included in the interviews

\section{Main sections of the topic guide}

- How and from where information is accessed and its accessibility

- General views and opinions towards cancer and early detection services

- Awareness of risk factors and public health campaigns

Interviews were carried out from June 2013 to February 2014. A total of 25 participants were involved in this study and each participant was interviewed on at least one occasion. Some individuals were interviewed on more than one occasion and a total of 33 interviews were conducted. Following the initial 15 interviews, theoretical sampling was employed and a further 18 interviews were conducted; 10 of these were first interviews with new participants and eight were repeat interviews. The repeat interviews were targeted at specific participants to gain a deeper understanding of issues they had raised in relation to the emerging categories and developing theory.

Out of the total 33 interviews, 22 were conducted in participants' homes (some follow-up interviews were conducted over the telephone). The remaining 11 interviews were conducted in different community centres based on the participant's location. The duration of interviews ranged from 15 minutes to 114 minutes. All interviews were audio-recorded using a digital voice recorder to ensure that participants' full accounts were captured. Immediately after leaving the interview venue, verbal reflective diary accounts were audio-recorded. Twenty-two audio data files were transcribed by a professional interview transcription service. The first author transcribed the remaining 11 audio data files. All transcribed data were transferred into NVivo10 software for data management and analysis. 


\section{Data analysis}

Data were analysed according to constructivist grounded theory analytical method (Charmaz, 2014). Line-by-line initial coding was performed and produced 308 initial codes (nodes). Multiple initial codes with characteristic similarity were then combined to create 113 themes. Subsequently, focused coding was used to combine multiple themes into 99 multiple properties. Based on their conceptual meaning, specificity, and close relationships, these multiple properties were collapsed into 14 categories. After the third and final stage of theoretical coding, these 14 categories and their 99 properties were further refined to 30 properties under eight emergent categories. Out of these eight emerging categories, the core category was selected based on its capability to capture the studied phenomena at a more conceptual level, its interlinking with all remaining categories, and its level of explanatory power of the major concept (Corbin \& Strauss, 2008). Figure 1 below illustrates the analytical process.

Figure 1: Process of Data Coding from Initial Coding to Constructing Categories

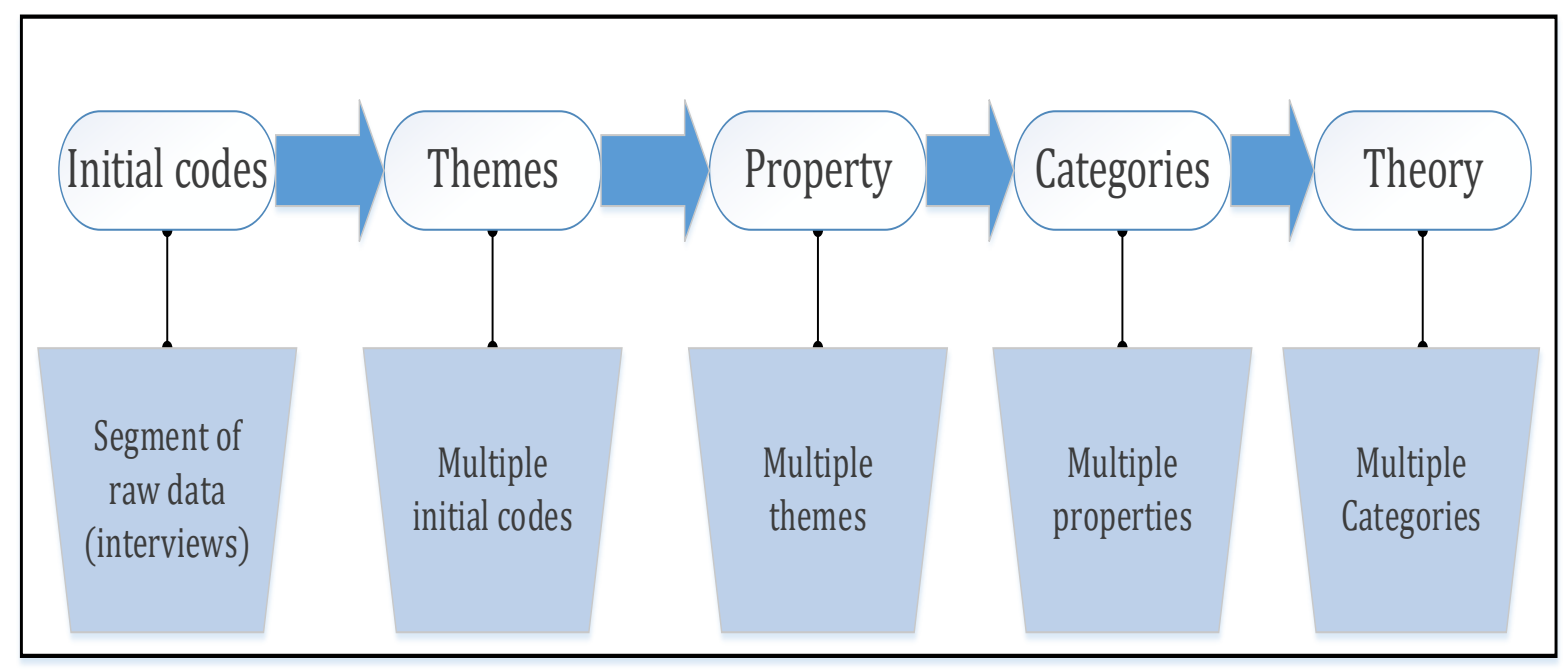

\section{Results}

Eight categories emerged. 'Cancer through black eyes' was identified as the core category and the remaining seven categories were classified as sub-categories: 'Cultural views'; 'Religious beliefs'; 'Avoiding Babylon'; 'Alienation'; 'Suspicious mind'; 'Advertisements and information influence very little', and 'Gap in service provision (Bridging the gap)'. 


\section{Cancer through black eyes}

Black men had their own way of viewing cancer. Black men did not see cancer as an illness that affects black people; recognition of any cancer type as a problem, including prostate cancer, was minimal. Cancer was not identified as a "black peoples' problem" in the way that other specific illnesses such as Sickle Cell disease and HIV were associated with this community. Regardless of the participants' background, they did not consider cancer to be a major health concern for black men. However, BAC participants repeatedly mentioned that community-based health campaigns supported by the National Health Service (NHS) helped them to recognise Sickle Cell disease as a black person's illness.

'People realise that Sickle Cell is our disease they kind of homed [honed] into it and were made aware of it, because of all the things and the NHS as well, because of all the publicity around it so you could do the same thing for cancer for prostate cancer' (SBAC, 04)

For BA participants, HIV/AIDS was more of an issue than cancer.

'It was AIDS before, nowadays AIDS is okay because at least you can sustain your life for long, so we are not exposed enough for cancer for long, that's why we don't know it' (FBA, 13)

Participants were unaware that black men were more likely to be diagnosed with prostate cancer than any other ethnic group. The perception that 'cancer is not our disease' was strong among both BA and BAC participants; most referred to non-consumption of processed food as one of the reasons for this belief. Participants used the terms 'processed food' and 'non-organic' as synonyms for all mass-produced foods. Participants from both communities believed that processed food and non-organic food was the main cause of cancer. There was a strong belief among participants that since they grew up consuming organic food, the problem of cancer was not associated with black people.

'We used to eat organic food. When you come to this country, in Europe or in a Western place there are a certain kind of food, all processed inorganic food, so if you are eating 
those kind of foods from your early age, your risk to getting cancer may be higher, so the black people for those reasons, they are less likely to get cancer. In my belief cancer is a white people thing' (FBA, 02)

Participants also reported other causes of cancer, such as age, genetics, sinfulness, engaging in too much sexual activity, and masturbation. The latter two causes were mentioned by participants as specific to the causation of prostate cancer.

If you have bad sexual behaviour, remember this is overactive, you get damage, so you're always sleeping with women, or you're playing with yourself all the time, you're going to damage it, ... your prostate get damaged, you get cancer' (FBAC, 05).

There was a strong belief among BAC participants that cancer was a deliberate strategy for population reduction. They questioned why, given the amount of money spent on cancer research, an enormous number of people were still affected by cancer. Considering the length of time cancer had been recognised as a major illness, they felt that there was no sufficient explanation as to why it was taking such a long time to eradicate the problem, other than that cancer was being used as a population reduction programme. To emphasise that cancer was a social-engineering project, participants used terms like 'deliberate', and 'they know what they are doing'. One BAC participant stated that:

'I know it's a bad thing to say, but they're wiping out people but they don't tell you. It's a secret project honest to God, they've got this excuse to tell you, you know smoking, this that, but they only put into your heads what they want you to know only to give in your head. I know that cancer research help making cancer better, finding a way of improving, but they've been doing this for years and there's no change, and I was saying, as I just said to you, they know what they are doing, cancer is a secret project' (SBAC, 01).

Late diagnosis was also linked with lack of awareness about cancer in the black community. This observation applied to both BA and BAC participants, regardless of generation. Some identified this lack of awareness as being the root cause of why black men did not consider cancer as an illness that could affect them. 
'I think prostate ... if you see it, cancer is a white men thing, man' (FBAC 001)

'It's just my thinking. I don't think for me black people are not that much vulnerable for cancer' (FBA, 03)

\section{Cultural views}

Black men's cultural views shaped a distinct way of looking at cancer and related issues, including cancer risk factors, and preventative measures to minimise the risks and early detection. Although it is recognised from existing literature that men from other ethnicities may find a Digital Rectal examination (DRE) an unpleasant experience and culturally sensitive, the degree of sensitivity articulated by participants in this study showed that a DRE for black men was a 'no-go' (FBA, 24) area. Culturally, it was considered disgraceful for a man to be subjected to a DRE, as this may conflict with being a 'proper' man.

'In our tradition men cannot open their anus for other one to go in, that's not culturally accepted, for men to open their anus for examination, culturally it's not acceptable. It is a very disgraceful thing because you will not consider like a man after that' $(F B A, 13)$

In the black community there was a specific cultural meaning attached to smoking. Smoking 'herbs' such as cannabis or marijuana, even though mixed with tobacco, was not considered the same as smoking a purely tobacco cigarette. Rather, smoking herbs was considered meditative, and Rastafarians would mainly use it as a ritual. Smoking herbs was considered to be healthy if performed with the right mind-set. This embedded philosophy and the cultural meaning attached to it indicated that BAC men considered herbs to be harmless, even if mixed with tobacco. Smoking herbs was also a sign of a peaceful and happier lifestyle, promoted through music in association with iconic figures such as Bob Marley and others. As mentioned by one participant, there was no perceived link between smoking herbs and cancer:

'Bob Marley for example, he's said to have smoked a lot of herbs. Anytime I get pictures of Bob Marley, when we see him, they show him with lots of herbs. Maybe it's not true but that's what they show, and he was singing all the time and he was peaceful, happy and so on, even though he's also supposed to have died of cancer. In fact he was, Bob Marley himself was strictly vegetarian, and that sort of lifestyle, so he then gets cancer, 
now how does that work, I'm not sure you know, you don't know for sure of the links, there's no links; you don't see the links' (SBAC, 04)

For BA participants, smoking was a sign of belonging to the higher social classes. Many grew up in a society where smokers were categorised as the elite. Hence, they believed that smoking was a status symbol that indicated joining the elite class.

'Most of the people think that smoking is for the rich people so they join the sector of smoking because they want to be on the member of high class people' (FBA, 06)

Although there were differences in the meaning and symbolisation attached to smoking in the $\mathrm{BA}$ and BAC context, recognition that smoking was a health hazard that increased the risk of getting cancer was negligible in both communities.

There was also a cultural belief that being heavy and putting on extra weight was associated with prosperity and affluence. The perception that 'big is beautiful' was mainly mentioned by first generation BA participants; a BA male with a high bodyweight was highly respected and regarded as wealthy. Being big was also considered a visible indicator in the community regarding a man's ability to look after his family. Among BAC men, being big was also important, but with a slightly different perspective relating more to the negative connotations of having a low body weight; being slim was a sign of poverty and deprivation. Regardless of the different perspectives on body image, both communities considered big was beautiful and sought after. BA participants stated that when they travelled back to their home countries, one of the common things that they had to address was their families', and especially their mothers', concerns about their weight. Gaining weight was seen as reassuring to the family, indicating that the person was leading a comfortable life abroad.

'Even now if I have to go back home my mom will be asking me, why are you not a little bigger, are you eating well and all those things, because they expect you to be big, muscular' (FBA, 06)

For second generation BA men fitness was perceived as more important than weight. 
'For older generation being big is good, but for younger like me there is change of mentality it's not being big, yeah, it's about fitness, you need to be fit' (SBA, 21)

Although views about weight differed between first and second generations, the perception of having physical superiority carried the same symbolism in both generations. Black men believed that they were physically stronger than others. They also believed that one of the benefits of having a superior physical presence was that they had a better immune system for dealing with illnesses like cancer.

'I don't know how, I can't explain it, but we are blessed as an African, because there are a lot of things which we can handle, our immunity can handle which this people's immunity can't handle it, because I think we are stronger than them, that is the difference' $(F B A, 10)$

In both BA and BAC culture, social hierarchy was important in various aspects, including communication and conveying information. Obeying the word or order of respected and older members of the community was widely practiced. Social status was perceived as important to both BA and BAC participants. However, for BA participants, status and authority were associated with occupation and with age. For BAC participants it was the style of communication that primarily commanded respect; preferably loud and authoritative.

"I think that is crucial, I think if he was a black doctor, "what you talking about, you have to come back, I'm booking your appointment and you're coming back here do you understand, it's serious [loud tone of voice]", that kind of talk will make him realise and say yes doctor, all right doctor, yeah man, I will come; you must show him you care for him: "listen, I'll phone you the day before to make sure that you're ready for this operation." This is what is lacking in health services, African doctors, who's familiar with the Caribbean and stuff like this' (SBAC, 11)

Participants had strong and fixed cultural views about what it meant to go to hospital. For both communities there was a culture of using traditional healers or taking traditional herbs to deal with illness rather than going to hospital. Many BAC and BA participants believed that 'Mother Nature' had always provided cures for any illness. Although participants acknowledged the 
developments in modern medicine, the majority of BA participants preferred to go to traditional healers or to seek religious remedies such as holy water and exorcism. Going to hospital was the very last option, only to be considered when people became very ill. This view applied both before and after participants had moved to the UK.

'Normally we don't go to doctor unless you are forced by illness to your bed, you don't go to the doctor. Most of the time we got traditional and religious things taking out the evil spirits from a lot of people this includes cancer, back pain, yeah, even can cure the HIV' $(F B A, 14)$

However, there were cultural differences in the justifications for not going to hospital. BA participants mentioned that African men (particularly first generation), living in western countries like the UK, expected to do well in life and be financially secure for themselves and their families back home. Participants referred to this as 'the dream' of African immigrants. For first-generation Africans, going to hospital was a sign of weakness. If fellow community members saw an African man visiting his General Practitioner (GP) frequently or going to hospital, he would be considered weak. Seeking medical attention was seen as a sign of weakness since illness could mean a man's dream to succeed was about to be crushed.

'Like, myself, I don't visit the GP that regularly, because it's like been a weak, like, sort of like, you can't achieve your dream, you know what I mean, you can't afford to be seen as a weak, you have no option except to make it so you have to be strong, yeah, you get me' $(F B A, 06)$

For BAC men it was about belonging, and a recurring expression articulated by this group was that 'Western medicine is not our thing'; described as 'Babylon'. These participants explained that they had their own 'medicine' (herbs) - which were prescribed by natural healers both in the Caribbean islands and in the UK. BAC men inherited this mantra of 'going to hospital is not our thing' from their parents. This was echoed by a number of BAC participants, who recalled being advised by their parents not to go to hospital as they considered hospital to be a road that leads to death. 
'Even my parents they never go, well my father never go to hospital he doesn't even, if somebody was in the hospital, even had a friend he was in the hospital and his friend sent him some things to help him you know some gifts. I was young, but he said you know we don't go to the hospital [begins to whisper]' (FBAC, 09)

\section{Religious beliefs}

Religious beliefs were another influencing factor on the views of black men towards cancer. The concept of eternal life was very important in terms of how participants viewed cancer. For BAC participants, especially those who followed the Rastafarian religion, one of the core elements of the religion was that once someone reached a high level of spirituality, he would receive eternal life and become immortal. As this gift of immortality was earned throughout life, it was important for the believer not to jeopardise receiving such a gift by questioning it once it had been received. Participants mentioned that for someone who reached this level of spirituality, illnesses like cancer were not a concern.

'These things go right into the roots of our belief system. One of the belief is a Rasta Man would say I cannot die, because I'm deemed with eternal life. So a lot of them evade the death issue. So when you buck up [meet up] on death or cancer, that can't bother me man, it is like cancer doesn't touch them, they'll say something like that cannot affect me because I am over that' (SBA, 04)

Although eternal life (immortality) was significant to both communities, there were different beliefs about the effect of eternal life. BAC men believed that once a person received eternal life, cancer would not affect them, while BA men believed that as a result of receiving eternal life, a person would be cured from cancer. The concept of eternal life was associated with individuals' high level of spiritual rituals. Even for religious people who did not claim to have a high level of spiritual rituals, cancer had some positive aspects by offering a different perspective of life. If a religious person was affected by cancer, it would change his life for the good, because as death approached, it was time to take life seriously in preparation to meet God. Thus, life would become more meaningful to a cancer patient and this belief would help individuals to do meaningful things that were acceptable in the eyes of God. 
'I'd just have to take life a lot more serious, I'd have to 'cause I know that my day is coming to an end and l'd be looking forward to meeting my creator actually, so not all bad news, it's not really bad news really' (SBA, 04)

\section{Avoiding Babylon}

Participants used the term 'Babylon' to magnify their disassociation with something that they needed to avoid. The term 'Babylon' had negative connotations in the light of the Rastafarian philosophy of belief system; 'Babylon' symbolised economic and political oppression. BAC participants in particular used this term often in referring to modern Western medicine, perceived as toxic and impure and the road to death. Some participants also considered healthcare professionals to be a part of Babylon.

'Nothing can touch lanl [you and me], me not going to Babylon doctor to fix me, I will go and get some herb, get some malunggay, some mariandina [herbs], and use that to cure me that's natural that's not Babylon' (SBAC, 20)

One participant discussed how a close friend had terminated his cancer treatment because of the adverse side effects. This participant was using his friend's condition to explain how western medicine ('Babylon') was harmful.

'He's going through, he's taken radiotherapy, yeah, then he, he, he done the first two and then he had a, he had, he had a nasty reaction, and then he's not gonna bother with, with the last process' (FBAC, 08)

Many participants mentioned that black men refused treatment so as not to suffer from the potential side effects of modern medicine in comparison with herbal remedies. However, a few participants also mentioned that some black men refused prostate cancer treatment as they preferred to give priority to their sex life, perceiving that prostate cancer treatment would have a negative impact on sexual function.

'One person had prostate cancer he's from Africa, western African. He has been referred to hospital and the hospital doctor asked him to take it out [the prostate], to remove it. He said "no, I love sex" " (FBA, 13) 


\section{Alienation}

Alienation was an axis around which participants' suspicion, mistrust and apprehensive views rotated. Participants felt unwanted and alienated by the social system, which breaks down population by age, ethnicity, and class. Participants spoke about their feelings of disfranchisement, referring to various institutions, including the healthcare system in the UK, as the main tools and mechanisms for control black people.

'About the blacks, they don't give a shit about the blacks. They don't give, they don't care about the blacks' (FBA, 11)

'The system is against black. If you look at everywhere healthcare, prison system, education, yeah, all of them, you know what they are doing? they will tell you that you are crazy then put you in hospital or jail that is where black men end up man' (FBAC, 05)

'I was born here. The mind-set isn't right. We've been messed up through the system man. You've just been messed up, they messed us up, but a lot of us aren't conscious of it... you've been inculcated into your head to hate hate yourself, not just our generation, it go back to slavery and it hasn't stopped.' (SBAC, 04)

\section{Suspicious mind}

Participants were uneasy about society's structure as a whole. Their suspicion of the healthcare system, the NHS as an organisation, and the healthcare professionals working within it was very apparent. The majority of BAC participants mentioned that the residue of past historical events like slavery made them apprehensive of doctors and their practices.

'As we have issues already as coming from slavery, the first thing we're thinking of, well they're gonna experiment on us but if you were white you'd probably think it's doctors, and you wouldn't think they're experimenting... well if you've been slavery and you're talking of even today we touched on some form of genocide' (SBAC, 17)

'My mom used to tell me when I was young, when you go to the doctor don't let him take your blood, let me explain. If you have our skin melanin, you heard the word melanin, the white man you've seen it all the actors, film stars they're always brown aren't they? A lot 
of them their skins are brown. You think it's tanned, no it isn't. They take our blood and then they pass it on and use it, because our melanin, you see' (FBAC, 01)

'All the things they've been doing with black people and the foetuses, how have they been getting the melanin? Where are they extracting the melanin from to now be selling melanin injections? Now they're telling you, you don't have to go on the sunbed they can sell you melanin injections. So we know that melanin comes from black people. So where is the... where, how are they getting that resource?' (SBAC, 17)

\section{Advertisements and information influence very little}

All participants agreed that cancer-related advertisements and information outlets did raise awareness about cancer. However, they strongly believed that in their current format, cancerrelated advertisements, available within mainstream mass media, had very little impact on raising awareness among black communities. One of the three most dominant reasons for this was that participants felt that cancer advertisements were linked to financial gain, with inconsistent money-driven health messages being relayed.

'Most of these cancer groups they don't get into diet, they can't get into diet, because some of their biggest sponsors are some of the things that have contributed to this, like fast food industries' (FBAC, 09)

'Well, there's advertisement straight away tells you money. When it comes to money it's just corruption isn't it? So there's always something at the back of it, you mix the truth with a half-truth, and mix a half-truth with a lie and then it seems like the truth. So they can tell you about the cigarette, stop smoking, but behind it there's something else really. It's deeper than that, it's not just a cancer' (FBAC, 05)

Advertisements were not perceived as specific or appealing to the black community and a more targeted, tailored message was considered a beneficial way of sending out the right message. Most participants perceived that information and advertisements were too general and did not target the black community. 
'Most advertisements are not cultural tailored ones, they're too general and they are not sensitive to others' cultural and others needs and characters to community, because of that it doesn't work for black community it doesn't that much' (FBA, 14)

Another related issue which was pointed out by few participants in order to highlight the degree of black people's sensitivity towards public-health campaigns came from the fear of being blamed for issues that were a burden for the wider society, like HIV, drugs, and crime. As further elaborated by one 26-year-old second-generation BA participant, publications that put black men as a centre of attention made black people anxious in the first instant as they perceived the publication to have a hidden agenda of blaming and finger pointing.

'If you put a black man image, it could be offensive and they treat it negatively and thinking you're stigmatising them. Believing this kind of thing is only actually going to [happen to] the black people. So they will ask 'why, what are you trying to say?' Don't forget black people get blamed for all sort of things like HIV, drug, crime, so if you put only black man they say 'here we go again' look the system here, what you trying to say, you're saying only black going to have this kind of disease. So, in that case they see the blame and finger pointing than the actual message. So, as a high priority they must get the balance right in that information they put [out] and even with actually in passing the message across. If white and black people being shown side by side on the poster, then they can see both side of the story' (SBA, 15)

\section{Gap in service provision (bridging the gap)}

Participants suggested that there was a gap within the health service in engaging with black men, and in providing cancer-related information that was relevant to black men. Many participants noticed this gap and suggested there was a need to bridge it.

'NHS could do more, if you see it, NHS and black people are two disconnected things, clearly there is a valid need for the gap between the NHS and the black communities to be bridged' (SBAC, 11)

Participants suggested that negotiating with the healthcare system to create black-led clinics was an effective way to bridge the gap between black men and the healthcare system. It was 
perceived that many black men did not want to go to NHS hospitals, mainly because of cultural issues, mistrust, or avoiding potential harms (Babylon). As a consequence, they did not access factual information about cancer; they were also not willing to uptake available cancer screening tests such as DRE, this meant that they often presented at a late stage if they were affected by cancer. Participants were also aware that facilities currently existed for other ethnicminority groups to accommodate specific needs regarding cancer and other chronic diseases such as diabetes. Participants were in favour of black-led health clinics with grass-roots level health promotion as an effective way to bridge the gap between black men and the healthcare system.

'Don't forget in each community groups there are health professionals ..., lot of nurses, doctors, they're one of the respected community members, if we ask them they will be happy to help as volunteer to promote awareness in the community, so we can use them and save a lot of money for the government' (FBA, 14)

'We need to put a service in place for our community that can act between the hospital and our community, a point of call' (SBAC, 17)

\section{Discussion}

Within this study, black men constructed their views based on their understandings of, and the meanings they ascribed to, social systems and establishments, such as the healthcare system. Their views towards cancer and cancer-related issues were closely linked to socially constructed perspectives of themselves and what being black means, the advantages and disadvantages of being black in society, and historical phenomena like slavery, which strongly influenced their perceptions of, and relationship with, Western medicine. As a result, black men appear reluctant to engage with cancer services.

Gaining a detailed understanding of the meaning of cancer and cancer-related issues from black men's perspectives helps us to understand why black men are less aware of cancer risk factors and early-detection services, as noted in previous studies (Waller et al., 2009). This understanding may also explain why, despite there being no evidence to suggest that black men have better or worse access to diagnostic services in the UK (Metcalfe et al., 2008), black men are less likely to attend early-detection services and often present late with symptoms (Austin 
et al., 2009; DH, 2011). The main screening methods are prostate-specific antigen (PSA), performed by taking a blood sample, and DRE, involving feeling the prostate gland through the rectum. For the black men participating in this study, both taking blood and undergoing rectal penetration were major barriers to being pro-active in presenting for screening.

Most participants in this study showed little awareness of risk factors, signs, and symptoms of cancer, including prostate cancer. Two quantitative studies carried out in the UK have produced similar findings (Rajbabu et al., 2007; Waller et al., 2009). These two quantitative studies did not provide an explanation as to the reasons for this lack of awareness. The in-depth qualitative approach adopted in this study showed that black men have low awareness about cancer because health-promotion endeavours do not present cancer through black eyes, using materials/mediums that are sensitive to the needs and cultural beliefs of black men.

Common unhealthy behaviours that are known to be major clinical cancer risks, such as smoking and unhealthy eating (Cancer Research UK, 2017c), have socially constructed meanings in the black community. These often bear important positive symbolisation through black eyes, which is influenced primarily by culture and religion. The findings indicated that BA men considered smoking to be a sign of status, associated with the elite and influential factions of society. In spite of BA men's reluctance to acknowledge the risks of smoking in relation to cancer, for BA men the perceived social benefits and significance of smoking are likely to outweigh the mainstream public-health warning. Similarly, for BAC men, smoking had a deeper meaning, particularly in terms of the consumption of herbs such as cannabis and marijuana. In the BAC community, smoking cannabis was not only socially acceptable, but often socially and religiously desirable. Cannabis and other herbs were believed to be conducive to good health, with an ability to prevent diseases, including cancer, and were often regarded as an effective natural remedy for cancer. Smoking herbs also played a significant role in religious rituals among followers of Rastafarianism. Far from being a cancer risk factor, smoking was perceived as a remedy and was positively encouraged. The marketing of cigarettes has been repeatedly targeted at the black community, particularly in the USA. For example, menthol cigarettes have been marketed to the black community as safer choices than non-menthol cigarettes (Rising \& Alexander, 2011). In addition, menthol cigarettes have been promoted as reflecting 'coolness' and sophistication (Rising \& Alexander 2011, Balbach et al., 2003). Sutton and Robinson (2004) identified four key types of message for menthol cigarettes including healthy/medicinal; fresh, 
refreshing, cool and crisp; youthful, silliness and fun; and an ethnic awareness targeting the black community. Successful marketing of cigarettes to the black community as sophisticated and cool fits well with our findings on black men's positive attributions of cigarette smoking as beneficial; physically, psychologically and socially. Thus, the effect of smoking through black eyes was contrary to the clinical message of current health promotion campaigns

Obesity is a major public-health problem in developed countries that accounts for $2-6 \%$ of total healthcare costs in several developed countries (World Health Organization, 2003). Systematic reviews indicate that obesity and being overweight predispose a person to different health problems, including cancer (Martinson et al., 2011; Misganaw et al., 2014). Participants in this current study reported that being overweight was perceived as a sign of prosperity. A USAbased study also reported that African-American teenagers of both genders perceived that being overweight was acceptable in their cultures (Barroso et al., 2010). However, prosperity was not mentioned amongst the reasons given by Barroso et al.'s (2010) participants. Despite these differences, black men's cultural expectations, and what being overweight symbolised, undermined the notion of it being a cancer risk factor.

Black men in this study were suspicious of authority and institutions, including the NHS, which they perceived to be a tool to control black men. Black men who came across cancer-related information provided by governmental organisations or advertisements broadcast in the mainstream media assumed that the information was a 'half-truth'. Thus, a top-down health promotion and information-giving approach would lack credibility and be unappealing through black men's eyes. Further, participants' feeling of alienation and suspicion, which widen the gap between service providers and black men to avoid 'Babylon', were reasons for black men to lack receptiveness to cancer related health promotion messages. Hence, it would be too simplistic to state that black men are entirely unaware of risk factors, resulting in vital misunderstandings from a public-health perspective. The important point to be understood by health promoters is that black men may appear less aware of cancer risk factors because they have their own interpretations of the risk factors, inextricably linked to culture and religion beliefs, and not because they have limited knowledge of the subject area. This study showed that bottom up health promotion is more preferable to increase black men's receptiveness to cancer related health promotion messages. 
Although this study has focused specifically on black men and their views on cancer, the findings may have broader applicability for healthcare professionals who come into contact with minority groups more generally. Understanding the health beliefs of different minority groups is important for designing effective cancer-related services. Healthcare professionals need to be equipped with cultural competency skills. Understanding how illness and treatment are perceived by different minority groups is essential if service delivery is to effectively target different communities and cultures within our highly multi-cultural healthcare environment.

\section{Study limitations}

The recruitment process included the use of print (posters) and radio advertisements. Participants who were recruited through the radio advertisement could be assumed to be black men with specific cultural and religious beliefs, since the advertisement was broadcast on the local Caribbean Radio station, whose target audience is black communities. These participants' high sense of belonging to a black identity could be reflected in their responses. Hence, the study might be subject to unintentional sampling bias. Secondly, given that black people have immigrated to the UK from over 60 countries (from both geographical regions), the findings of this qualitative study cannot be generalised to all black men, and need to be considered in context.

\section{Implications for practice and research}

The findings from this study have implications for health care professionals and policy makers who engage in public health campaigns for ethnic minority groups. Although this study focused solely on the views of black men, there are pertinent issues that could be relevant to other cultural groups, both in and outside the UK. For example, our study indicated differences between the views of first and second generation participants. Other studies have reported a 'healthy migrant' advantage for first generation immigrants to a host country, regardless of socioeconomic position (Anson, 2004; Tarnutze et al., 2012; Vandenheede et al., 2015). However, migrant health and mortality tend to converge to the levels of the host country with increasing duration of stay over subsequent generations (Parkin and Khlat, 1996; Vandenheede et al., 2015). Hence, there is an argument for strongly targeting health promotion campaigns at first generation individuals to discourage uptake of high-risk health behaviours and encourage cessation of unhealthy behaviours such as unhealthy eating and smoking (Vandenheede et al., 2015). 
Our findings indicated that cancer-related information provided by large government and charitable organisations was not specifically focused on black men; current information formats were unappealing even when they featured black men. Participants perceived that they were being 'blamed' whereas advertisers presumably perceive that they are engaging positively with a hard to reach community. Cancer-related health campaigns could consider the theory of cancer through black eyes as an additional resource in the preparation of future health campaigns for black men, carried out in collaboration with black community organisations.

Health information needs to be conveyed more effectively to encourage black men to acknowledge cancer as a health threat. Nurses and other healthcare professionals should be aware of the cultural and religious influences, which effect the receptiveness of black men towards health promotions. For example, an authoritarian manner of communication was preferred by black men. Pre-registration nursing training programmes, which include cultural competency modules focused on how illness and cure are understood by different cultures, could be beneficial. This would be particularly applicable to public-health related nursing programmes, where the importance of familiarity with the cultural understanding of black men is important in providing effective health-promotion information, and to encourage early detection and early diagnosis of disease conditions such as prostate cancer.

This study provides a deep understanding of the views of black men towards cancer. However, this qualitative study included a small sample, making generalisations of the findings difficult. Further quantitative or mixed-methods research is needed to gain a broader understanding of black men's views towards cancer. A more detailed examination of the views of each of the two sub-groups (BA and $B A C$ ) and of different generations of participants (first and second) is warranted. Although there were similarities in views across sub-groups and generations, there were important differences and these differences justify a more detailed exploration to ensure health care services are targeted appropriately. However, black men in this study were suspicious about clinical research and mistrusted the healthcare system and healthcare professionals. Involving black men in further research is likely to be challenging. The lead author of this study is a black African man and had an insider advantage; this approach to recruitment may be helpful for other researchers who wish to carry out work in this area. 


\section{Conclusions}

This study showed that socio-political economic issues and cultural and religious beliefs affected the ways in which black men perceived cancer. The views that these black men describe result in feelings of suspicion, conspiracy theories and mistrust of the UK healthcare system's otherwise positive intentions to provide health provision using modern Western medicine. This undermines their engagement with health care services and reduces the effectiveness of current health promotion methods and advertisements. The cultural similarities and differences between $\mathrm{BA}$ and $\mathrm{BAC}$ men need to be taken into account by health care professionals, including public health campaigners and policy makers, to develop cancers services that are inclusive in order to reduce health inequality. 


\section{References}

Abraído-Lanza, A. F., Armbrister, A. N., Flórez, K. R., Aguirre, A. N. (2006). Toward a theorydriven model of acculturation in public health research. Am J Public Health, 96(8), 1342-6.

Anson, J. (2004). The migrant mortality advantage: a 70 month follow-up of the Brussels population. Eur J Popul. 20, 191-218

Austin, K. L., Power, E., Solarin, I., Atkin, W. S., Wardle, J., \& Robb, K. A. (2009). Perceived barriers to flexible sigmoidoscopy screening for colorectal cancer among UK ethnic minority groups: A qualitative study. J Med Screen. 16(4), 174-179.

Balbach, ED., Gasior, RJ., Barbeau, EM. (2003). RJ Reynold's targeting of African Americans: 1988-2000. Am J Public Health. 93, 822-827

Barroso, C., Peters, R., Johnson, R., Kelder, S., \& Jefferson, T. (2010). Beliefs and Perceived Norms Concerning Body Image among African-American and Latino Teenagers. J Health Psychol. 15(6), 858-870.

Ben-Shlomo, Y., Evans, S., Ibrahim, F., Patel, B., Anson, K., Chinegwundoh, F., Corbishley, C., Dorling, D., Thomas, B., Gillatt, D., Kirby, R., Muir, G., Nargund, V., Popert, R., Metcalfe, C., Persad, R. (2008). The risk of prostate cancer amongst black men in the United Kingdom: The PROCESS cohort study. Eur Urol. 53(1), 99-105.

Brown, D. R., Wilson, R. M., Boothe, M. A., \& Harris, C. E. (2011). Cervical cancer screening among ethnically diverse black women: Knowledge, attitudes, beliefs, and practices. J Natl Med Assoc. 103(8), 719-28.

Burr, V. (2003). Social Constructionism. Routledge: East Sussex, United Kingdom.

Cancer Research UK. (2017a). Cancer mortality for common cancers. Accessed 21.04.17. http://www.cancerresearchuk.org/health-professional/cancer-statistics/mortality/commoncancers-compared\#heading-One 
Cancer Research UK. (2017b). Prostate cancer risks and causes. Accessed 21.04.17 http://about-cancer.cancerresearchuk.org/about-cancer/prostate-cancer/risks-causes

Cancer Research UK. (2017c). Causes of cancer and reducing your risk. Accessed 21.04.17 http://www.cancerresearchuk.org/about-cancer/causes-of-cancer

Charmaz, K. (2005). Grounded theory in the $21^{\text {st }}$ century: Applications for advancing social justice studies. In N. K. Denzin, \& Y. S. Lincoln (Eds.). (3 ${ }^{\text {rd }}$ Ed). The SAGE Handbook of Qualitative Research (pp. 507-535). Sage Publications Inc.: Thousand Oaks, CA.

Charmaz, K. (2006). Constructing Grounded Theory: A Practical Guide through Qualitative Analysis. Sage Publications: London, United Kingdom.

Charmaz, K. (2014). Constructing Grounded Theory (2 ${ }^{\text {nd }}$ Ed.). London, United Kingdom: SAGE.

Corbin, J., \& Strauss, A. L. (2008). Basics of Qualitative Research: Techniques and Procedures for Developing Grounded Theory ( $3^{\text {rd }}$ ed.). Thousand Oaks, CA: SAGE.

Dein, S. (2004). Explanatory models of and attitudes towards cancer in different cultures. Lancet Oncol. 5(2), 119-24.

Department of Health. (2011). Improving Outcomes: A Strategy for Cancer. Department of Health: London, United Kingdom.

Freeman, H. P. (2004). Poverty, culture, and social injustice: Determinants of cancer disparities. CA Cancer J Clin, 54(2), 72-77.

Jones, A., \& Chinegwundoh, F. (2014). Update on prostate cancer in black men within the UK. ecancer, 8(455), 1-10. dio: 10.3332/ecancer.2014.455

Gordon-Dseagu, V. (2006). Cancer and Health inequalities: An introduction to current evidence. Cancer Research UK. Accessed 21.04.17 http://www.cancerresearchuk.org/prod_consump/groups/cr_common/@nre/@pol/documents/general content/crukmig_1000ast-3344.pdf. 
Kohnert, D. (2007). African Migration to Europe: Obscured Responsibilities and Common Misconceptions. GIGA: Hamburg, Germany.

Martinson, M. L., Teitler, J. O., \& Reichman, N. E. (2011). Health across the life span in the United States and England. Am J Epidemiol, 173(8), 858-865.

Metcalfe, C., Evans, S., Ibrahim, F., Patel, B., Anson, K., Chinegwundoh, F., Corbishley, C., Gillatt, D., Kirby, R., Muir, G., Nargund, V., Popert, R., Persad, R.,Ben-Shlomo, Y. (2008). Pathways to diagnosis for black men and white men found to have prostate cancer: The PROCESS cohort study. Br J Cancer, 99(7), 1040-1045.

Misganaw, A., Mariam, D. H., Ali, A., \& Araya, T. (2014). Epidemiology of major noncommunicable diseases in Ethiopia: A systematic review. J Health Popul Nutr, 32(1), 1-13.

National Cancer Institute. (2017). Cancer health disparities. Accessed 21.04.17 https://www.cancer.gov/about-nci/organization/crchd/cancer-health-disparities-fact-sheet\#q9 Parkin, DM., Khlat, M. (1996). Studies of cancer in migrants: rationale and methodology. Eur J Cancer. 32: 761-771

Pedersen, V. H., Armes, J., \& Ream, E. (2012). Perceptions of prostate cancer in black African and black Caribbean men: A systematic review of the literature. Psychooncology, 21(5), 457468.

Rajbabu, K., Chandrasekera, S., Zhu, G., Dezylva, S., Grunfeld, E. A., \& Muir, G. H. (2007). Racial origin is associated with poor awareness of prostate cancer in UK men, but can be increased by simple information. Prostate Cancer Prostatic Dis, 10(3), 256-260.

Rising, J., Alexander, L. (2011). Marketing of menthol cigarettes and consumer perceptions. Tob Induc Dis, 9 (suppl 1):S2

Siegel, R., Naishadham, D., \& Jemal, A. (2013). Cancer statistics, 2013. CA Cancer J Clin, 63(1), 11-30. 
Sutton, D., Robinson, RG., (2004). The marketing of menthol cigarettes in the United States: populations, messages, and channels. Nicotine Tob Res. 6 (suppl 1), S55-S65

Tarnutzer, S., Bopp, M., SNC Study Group. (2012). Healthy migrants but unhealthy offspring? A retrospective cohort study among Italians in Switzerland. BMC Public Health. 12: 1104

The Prostate Cancer Charity. (2008). Ethnibus Research for the Prostate Cancer Charity. The Prostate Cancer Charity: London, United Kingdom.

Vandenheede, H., Willaert, D., De Grande, H., Simoens, S., Vanroelen, C. (2015). Mortality in adult immigrants in the 2000s in Belgium: a test of the 'healthy-migrant' and the 'migration-asrapid-health-transition' hypotheses. Trop Med Int Health. 20(12), 1832-1845

Waller, J., Robb, K., Stubbings, S., Ramirez, A., Macleod, U., Austoker, J., Hiom, S., Wardle, J. (2009). Awareness of cancer symptoms and anticipated help seeking among ethnic minority groups in England. Br J Cancer, 101 Suppl 2, S24-S30.

Webb, R., Richardson, J., Esmail, A., \& Pickles. A. (2004). Uptake for cervical screening by ethnicity and place-of-birth: A population-based cross-sectional study. J Public Health, 26(3), 293-296.

White, A. K., Thomson, C. S., Forman, D., \& Meryn, S. (2010). Men's health and the excess burden of cancer in men. European Urology Supplements, 9(3), 467-470.

World Health Organization. (2003). Obesity and overweight. Accessed 21.04.17

http://www.who.int/dietphysicalactivity/media/en/gsfs_obesity.pdf 